Revista Brasileira de Agricultura Irrigada v.11, nº.8, p. 2111 - 2119, 2017

ISSN 1982-7679 (On-line)

Fortaleza, CE, INOVAGRI - http://www.inovagri.org.br

DOI: $10.7127 /$ rbai.v11n800689

Protocolo 689.17 - 28/05/2017 Aprovado em 10/08/2017

\title{
PRODUÇÃO ORGÂNICA DA ALFACE EM SUBSTRATO FERTILIZADO COM ÁGUA AMARELA E MANIPUEIRA
}

Narcísio Cabral de Araújo ${ }^{1}$, Vera Lucia Antunes de Lima $^{2}$, Leandro Fabrício Sena ${ }^{3}$, Jailton Garcia Ramos ${ }^{3}$, Vitória Edclecia Borges ${ }^{3}$, Francisco de Assis Bandeira ${ }^{4}$

\section{RESUMO}

Uso agrícola de águas amarelas e manipueira é uma opção atrativa do ponto de vista econômico, em razão da ciclagem dos nutrientes e redução de custos com aquisição de fertilizantes minerais. Este trabalho objetivou avaliar a produção da alface Crespa Cristina cultivada em substrato fertirrigado com urina humana e manipueira tratadas por processo de digestão anaeróbica, como fonte alternativa de fertilizante. $\mathrm{O}$ experimento foi conduzido em casa de vegetação, o delineamento experimental foi o inteiramente casualizado, composto por oito tratamentos e três repetições. Os tratamentos consistiram por apenas o substrato (Testemunha); e o substrato fertirrigado com solução mineral composta por NPK, urina humana, manipueira, urina humana mais manipueira, duas vezes a dose de urina humana, duas vezes a dose de manipueira e duas vezes a dose de urina humana mais manipueira. $\mathrm{O}$ substrato foi composto por solo e esterco bovino não curtido na proporção de 2: $1 \mathrm{v} / \mathrm{v}$. Aos 38 dias após o transplantio foram avaliadas número de folhas, altura de plantas, diâmetro caulinar, massa fresca da parte aérea, massa fresca comercial, massa seca da parte aérea e raízes da alface. A análise estatística indicou que só não houve diferença estatística significativa para a variável altura de planta. As maiores médias foram obtidas através do substrato fertirrigado com urina humana mais manipueira, duas vezes manipueira e duas vezes as doses de urina humana mais manipueira, respectivamente. Concluiu-se que tanto as doses duplas de manipueira e a associação dos dois efluentes apresentam potencial fertilizador para a cultura da alface, podendo ser utilizados como fonte de nutrientes.

Palavras-chave: Lactuca sativa L., urina humana, uso agrícola de resíduos orgânicos, ecossaneamento.

\section{ORGANIC PRODUCTION OF LETTUCE IN FERTILIZED SUBSTRATE WITH YELLOW AND CASSAVA WASTEWATER WATER}

\footnotetext{
${ }^{1}$ Doutor em Engenharia Agrícola, UFCG. e-mail: narcisioaraujo@gmail.com

${ }^{2}$ Professora Titular, UFCG. e-mail: antuneslima@gmail.com

${ }^{3}$ Mestrandos em Engenharia Agrícola, UFCG. e-mails: leandrofsena@hotmail.com; jailtonbiossistemas@gmail.com; edicleciaborges@gmail.com

${ }^{4}$ Mestre em Engenharia Química, USP. E-mail: tiquinhobandeira@hotamil.com
} 


\begin{abstract}
Agricultural use of yellow water is an attractive option from the economic point of view, due to the cycling of nutrients and reduction of costs with the acquisition of mineral fertilizers. This work aimed to evaluate the production of Crespa Cristina lettuce cultivated in substrate fertirrigado with human urine and cassava wastewater treated by anaerobic digestion process, as an alternative source of fertilizer.The experiment was conducted in a greenhouse The experimental design was completely randomized, with eight treatments and three replicates.. The treatments consisted of only the substrate (Control); And the substrate fertirrigated with mineral solution composed of NPK, human urine, cassava wastewater, human urine more cassava wastewater, twice the dose of human urine, twice the dose of cassava wastewater and twice the dose of more cassava wastewater human urine. The substrate was composed of 2:1 $\mathrm{v} / \mathrm{v}$ untreated soil and bovine manure. The number of leaves, plant height, stem diameter, fresh shoot weight, commercial fresh mass, dry shoot mass and lettuce roots were evaluated at 38 days after transplanting. Statistical analysis indicated that there was no statistically significant difference for the plant height variable. The highest averages were obtained through the fertirrigated substrate with more manipulative human urine, twice manipueira and twice the doses of human urine more manipulative, respectively. It was concluded that both the double doses of manipueira and the association of the two effluents present fertilizer potential for lettuce cultivation, and can be used as a source of nutrients.
\end{abstract}

Keywords: Lactuca sativa L., urine human, agricultural use of organic waste, ecosystem.

\section{INTRODUÇÃO}

A alface (Lactuca sativa L.) é uma das hortaliças folhosas de maior importância comercial e de maior consumo em todo o mundo. No Brasil, figura entre as principais hortaliças, no que se refere à produção, à comercialização e ao valor nutricional (OLIVEIRA et al., 2010). Segundo Ferreira et al. (2015) nos últimos 15 anos sua área plantada passou de 31.000 ha para aproximadamente 35.000 ha, sendo de grande importância para o consumo humano como fonte de sais minerais, vitaminas e fibras.

O aumento do custo dos fertilizantes minerais e a crescente poluição ambiental fazem do uso de resíduos orgânicos na agricultura uma opção atrativa do ponto de vista econômico, em razão da ciclagem de $\mathrm{C}$ e nutrientes (SILVA et al., 2010). Neste contexto, urina humana e manipueira apresentam-se como excelentes fertilizantes orgânicos, pois contem quantidades significativas de macro e micronutrientes essenciais para as plantas.

Objetivando reciclar os nutrientes contidos na urina humana Pradhan et al.
(2007), avaliaram crescimento, produção e qualidade de repolho fertilizado com urina humana em comparação a fertilizantes industrializados, observaram que os melhores resultados de crescimento e a produção foram obtidos através das fertilizações com urina humana. Rios (2008) avaliou o uso de diferentes concentrações de urina humana como solução nutritiva em comparação a solução nutritiva convencional no cultivo hidropônico da alface (Lactuca sativa), resultou que o crescimento, teores de nutrientes e a produção da alface fertirrigada com urina humana não diferenciou estatisticamente do tratamento controle (solução nutritiva convencional). Egigu et al. (2014) estudaram o crescimento, a produção e a qualidade microbiológica de tomate $\mathrm{e}$ beterraba fertilizadas com urina humana em comparação a adubação química sintética. Encontraram os melhores resultados de crescimento e produção com aplicação de urina humana e que não houve diferença significativa entre tratamentos para a qualidade microbiológica dos frutos do tomateiro e das raízes da beterraba. Araújo et al. (2015a) avaliaram o crescimento, produtividade $\mathrm{e}$ 
composição química de milho cultivado em sistema hidropônico fertirrigado com doses crescentes de urina humana e concluíram que o efluente mostrou-se eficaz para cultivar forragem verde hidropônica do milho, podendo substituir a solução nutritiva utilizada. Santos Júnior (2015) buscando analisar a viabilidade do aproveitamento da urina humana diluída em efluente doméstico na irrigação de plantas de milheto, concluíram que a adição de $4,5 \%$ de urina humana no efluente doméstico proporciona resultados de massa de grãos e eficiência do uso da água semelhante ao observado em plantas com fertilização mineral recomendada. E Santos et al. (2016) utilizaram urina humana como fonte de nutrientes para grama Bermuda, concluíram que o uso da urina humana diluída promoveu bom desenvolvimento e acumulo adequado de nutrientes no tecido das plantas.

Quanto ao uso agrícola da manipueira, Dantas et al. (2015) objetivando, avaliar o crescimento do girassol fertilizado com manipueira, concluíram que o uso do efluente proporcionou um desenvolvimento mais adequado das plantas e recomendaram seu uso como fonte de nutrientes para a cultura estudada. Duarte et al. (2012) e Santos et al. (2010), analisaram o uso da manipueira no cultivo da alface e concluíram que o efluente serviu como fonte de adubação para a cultura. Nos últimos anos diversas outras pesquisas analisando $o$ potencial fertilizante na manipueira em cultuaras agrícolas foram publicadas (SANTOS et al., 2010; SCHWENGBER et al., 2010; ARAÚJO et al., 2012; DUARTE et al., 2012; SILVA JUNIOR et al., 2012; BARRETO et al., 2013; BARRETO et al., 2014; ARAÚJO et al., 2015b; DANTAS et al., 2015; LEAL, LEAL \& ALBUQUERQUE, 2015; PESSUTI et al., 2015).
Este trabalho objetivou avaliar a produção orgânica da alface cultivada em solo fertilizado com urina humana e manipueira como fontes alternativas de fertilizantes.

\section{MATERIAL E MÉTODOS}

Esta pesquisa foi realizada entre os meses de setembro a novembro de 2016. O experimento foi conduzido em uma casa de vegetação instalada no Campus I da Universidade Federal de Campina Grande (UFCG), na cidade de Campina Grande ( $7^{\circ} 13^{\text {, }}$ 50 ” S, 35०52' 52” W, $551 \mathrm{~m}$ de altitude), estado da Paraíba, Brasil. A casa de vegetação possui uma área de $640 \mathrm{~m}^{2}$, estrutura metálica, sendo do tipo cobertura e arco, coberta com polietileno de baixa densidade de $150 \mu \mathrm{m}$ e laterais revestidas com tela de sombreamento com índice de proteção de $80 \%$. No ambiente de pesquisa, foram montadas unidades experimentais compostas por vaso-planta. Os vasos utilizados eram de plástico com 4,5 L de capacidade unitária, instalados em espaçamento de $0,45 \mathrm{~m}$ x 0,45 m e colocados sob base de tijolos.

Cada vaso foi perfurado na base para introdução de um dreno com $12 \mathrm{~cm}$ de comprimento e $6 \mathrm{~mm}$ de diâmetro nominal, a qual foi acoplada a uma garrafa PET com 0,50 L de capacidade para coleta do efluente de drenagem, visando permitir a recirculação do mesmo. No preenchimento, os vasos receberam uma camada de $0,100 \mathrm{~kg}$ de brita zero que cobriu a base e outra de $4,0 \mathrm{~kg}$ de um substrato composto por um solo franco argiloso e esterco bovino (EB) (Tabela 1) na proporção de 2: 1 v/v (duas partes de solo para uma parte de esterco bovino).

Tabela 1. Caracterização físico-química do solo e esterco bovino utilizados no substrato do experimento.

\begin{tabular}{|c|c|c|c|c|c|c|c|c|c|c|c|}
\hline \multicolumn{12}{|c|}{ Solo } \\
\hline pH $\left(\mathrm{H}_{2} \mathrm{O}\right)$ & CE & $\mathrm{CO}$ & MO & \multirow{2}{*}{$\frac{\text { d }}{\mathrm{g} \mathrm{cm}^{-3}}$} & Al & Mg & $\mathbf{C a}$ & $\mathbf{K}$ & $\mathrm{Na}$ & $\mathbf{P}$ & $\mathbf{S}$ \\
\hline 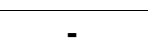 & $\mathrm{mS} \mathrm{cm}^{-1}$ & \multicolumn{2}{|c|}{$\ldots \ldots . . \% \ldots$} & & & & $\ldots \ldots$ & imolc & & & \\
\hline 5,63 & 0,19 & 1,60 & 1,83 & \multirow{2}{*}{\multicolumn{3}{|c|}{$\begin{array}{ccc}1,13 & 0,00 & 3,50 \\
\text { Esterco Bovino (EB) }\end{array}$}} & 1,75 & 0,42 & 2,37 & 1,82 & 6,86 \\
\hline & & & & & & & & & & & \\
\hline
\end{tabular}




\begin{tabular}{|c|c|c|c|c|c|c|c|c|}
\hline $\mathbf{p H}\left(\mathrm{H}_{2} \mathrm{O}\right)$ & $\mathbf{C E}$ & MO & $\mathbf{N}$ & $\mathbf{P}$ & $\mathbf{K}$ & $\mathbf{C a}$ & Mg & $\mathbf{S}$ \\
\hline 2 & $\mathrm{mS} \mathrm{cm}^{-1}$ & $\%$ & & & & & & \\
\hline 7,30 & 1,03 & 12,03 & 5,25 & 0,78 & 3,98 & 23,16 & 4,58 & 1,76 \\
\hline
\end{tabular}

A urina humana (U) utilizada no experimento foi coletada em três residências unifamiliar e posteriormente armazenada em balde de plástico com capacidade para 20,0 L mantido hermeticamente fechado durante 90 dias, antes de ser utilizada. A manipueira (M) foi coletada em uma casa de farinha localizada no distrito de Jenipapo, Município de Campina Grande, PB e armazenada por um período de 120 dias, em um recipiente de plástico com capacidade para 85,0 litros, que foi fechado deixando um espaço vazio de $10 \mathrm{~cm}$ no seu interior. Na tampa do balde foi instalada uma mangueira com a outra extremidade mergulhada num recipiente com água na altura de $10 \mathrm{~cm}$, para a saída dos gases geradas durante a biodigestão do efluente.

Após o período de armazenamento, a urina humana e a manipueira foram analisadas, segundo metodologia preconizada no Standard Methods for Wastewater (APHA, 2005), cujos parâmetros estão apresentados na Tabela 2.

Tabela 2. Caracterização físico-química da urina humana e da manipueira utilizada no experimento.

\begin{tabular}{|c|c|c|c|c|c|c|c|c|}
\hline \multirow[b]{2}{*}{ Efluentes } & \multicolumn{8}{|c|}{ Parâmetros } \\
\hline & NTK & $\mathbf{N}-\mathrm{NH}_{3}$ & $\mathrm{P}-\mathrm{PO}_{4}{ }^{-3}$ & $\mathbf{K}$ & $\mathbf{N a}$ & $\mathrm{Ca}+\mathrm{Mg}$ & pH & $\mathbf{C E}$ \\
\hline & & & . & -1 . & & & - & $\mathrm{mS} \mathrm{cm}^{-1}$ \\
\hline Urina & 8,70 & 6,74 & 0,325 & 1,10 & 2,45 & 0,034 & 9,32 & 42,7 \\
\hline Mani. & 1,68 & 0,93 & 0,338 & 3,95 & 0,14 & 2,800 & 4,73 & 11,75 \\
\hline
\end{tabular}

NTK: Nitrogênio Total Kjeldahl; $\mathrm{N}-\mathrm{NH}_{3}$ : Nitrogênio Amoniacal; $\mathrm{P}-\mathrm{PO}_{4}{ }^{-3}$ : Ortofosfato solúvel; K: Potássio; $\mathrm{Na}$ : Sódio; $\mathrm{Ca}+\mathrm{Mg}$ : dureza total; pH: Potencial hidrogeniônico e CE: Condutividade Elétrica.

O delineamento experimental adotado foi inteiramente casualizado, com três repetições e oito tratamentos, totalizando 24 parcelas experimentais. Os tratamentos consistiram por apenas o substrato $\left(\mathrm{T}_{1}-\mathrm{EB}\right)$, composto por duas partes de solo para uma parte de esterco bovino não curtido; fertirrigações com solução composta por NPK $\left(\mathrm{T}_{2}-\mathrm{NPK}\right)$; apenas urina humana $\left(\mathrm{T}_{3}-\mathrm{U}\right)$; apenas manipueira $\left(\mathrm{T}_{4}-\mathrm{M}\right)$; urina humana mais manipueira $\left(\mathrm{T}_{5}-\mathrm{U}+\mathrm{M}\right)$; duas vezes a dose de urina humana $\left(\mathrm{T}_{6}-2 \mathrm{x} \mathrm{U}\right)$; duas vezes a dose de manipueira $\left(\mathrm{T}_{7}-2 \times \mathrm{M}\right)$ e duas vezes a dose de urina humana mais manipueira $\left(\mathrm{T}_{8}-\right.$ $2 \times$ UM).

Os fertilizantes minerais foram compostos por ureia $(45,9 \%$ de $\mathrm{N})$, superfosfato simples $\left(18,9 \%\right.$ de $\left.\mathrm{P}_{2} \mathrm{O}_{5}\right)$ e cloreto de potássio $\left(60 \%\right.$ de $\left.\mathrm{K}_{2} \mathrm{O}\right)$. Estes foram previamente triturados e dissolvidos em água para posterior fertirrigação do substrato. Após o preparo das soluções procedeu-se às fertirrigações aplicando os tratamentos. Em cada parcela foram aplicados o equivalente a $100 \mathrm{mgN} \mathrm{kg}{ }^{-1}$ de solo, $300 \mathrm{mgP} \mathrm{kg}^{-1}$ de solo e $150 \mathrm{mgK} \mathrm{kg}^{-1}$ de solo, conforme recomendações de Novais et al. (1991), ou seja, para o tratamento $2\left(\mathrm{~T}_{2}-\mathrm{NPK}\right)$ foram aplicados $4,8 \mathrm{gP}_{\text {vaso }}{ }^{-1}, 0,75 \mathrm{gN}_{\text {vaso }}{ }^{-1}$ e 0,60 gK vaso ${ }^{-1}$.

As quantidades de urina humana $\mathrm{e}$ manipueira aplicadas em cada parcela foram estimadas com base nas concentrações de nitrogênio e potássio presente nos efluentes e a dose recomendada por Novais et al. (1991) (100 $\mathrm{mgN} \mathrm{kg}^{-1}$ de solo e $150 \mathrm{mgK} \mathrm{kg}^{-1}$ de solo), ou seja, para o tratamento 3 ( $\left.\mathrm{T}_{3}-\mathrm{U}\right)$, aplicouse $35 \mathrm{~mL}$ de urina por vaso; tratamento $4\left(\mathrm{~T}_{4}\right.$ M) aplicou-se $114 \mathrm{~mL}$ de manipueira por vaso; tratamento $5\left(\mathrm{~T}_{5}-\mathrm{U}+\mathrm{M}\right)$, aplicou-se $35 \mathrm{~mL}$ de urina mais $114 \mathrm{~mL}$ de manipueira por vaso; tratamento $6\left(\mathrm{~T}_{6}-2 \times \mathrm{U}\right)$, aplicou-se $70 \mathrm{~mL}$ de urina por vaso; tratamento $7\left(\mathrm{~T}_{7}-2 \times \mathrm{M}\right)$ aplicou-se $228 \mathrm{~mL}$ de manipueira por vaso e tratamento $8\left(\mathrm{~T}_{8}-2 \times \mathrm{UM}\right)$, aplicou-se $70 \mathrm{~mL}$ de urina mais $228 \mathrm{~mL}$ de manipueira.

Terminada as fertirrigações o substrato foi colocado em capacidade de campo e mantido em repouso por um período de oito dias. Transcorrido este tempo, realizou-se o transplantio, colocando uma muda de alface cultivar Crespa Cristina por vaso.

A irrigação era realizada com água de chuva com condutividade elétrica de $0,04 \mathrm{dS}$ 
$\mathrm{m}^{-1}$ captada na cobertura da casa de vegetação e armazenada em um reservatório de PVC. O volume de água era aplicado manualmente com turno de rega de um dia, mantendo o solo sempre próximo à capacidade de campo e recirculando o drenado da irrigação anterior.

A avaliação de crescimento e produção foi realizada aos 38 dias após o transplantio (DAT), através de medições de altura de planta (AP), diâmetro caulinar (DC) e número de folhas (NF). Todas as plantas foram coletadas e acondicionadas em sacos de papel, separando-se a parte aérea da zona radicular, previamente identificados, para pesagem e determinação das massas fresca da parte aérea (MFPA) e massa fresca comercial (MFC). A MFC foi determinada considerando a massa das plantas obtida após a retirada de folhas sujas, senescentes e doentes. Posteriormente, o material foi levado para secagem em estufa com circulação forçada de ar e temperatura controlada em $65{ }^{\circ} \mathrm{C}$ durante 72 horas. Após a secagem foram realizadas as determinações da massa seca da parte aérea (MSPA) e massa seca da raiz (MSR).

Os resultados das variáveis estudadas foram submetidos a análise de variância, através do software ASSISTAT v. 7.7 Beta
(SILVA; AZEVEDO, 2016), e as médias comparadas pelo teste de Tukey a nível de 5\% de probabilidade.

\section{RESULTADOS E DISCUSSÃO}

A Tabela 3 apresenta os resultados de comparação de médias, pelo teste de Tukey a 5 $\%$ de probabilidade, para as variáveis número de folhas (NF), altura de plantas (AP), diâmetro caulinar (DC), massa fresca da parte aérea (MFPA), massa fresca comercial (MFC), massa seca da parte aérea (MSPA) e massa seca da raiz (MSR), da alface, em função dos tratamentos.

Dos resultados encontrados observa-se, que com exceção da altura de plantas, a análise de variância indicou que houve diferença estatística significativa entre os tratamentos para as variáveis: número de folhas ( $\mathrm{p}<0,01)$, diâmetro caulinar $(\mathrm{p}<0,05)$, massa fresca da parte aérea $(\mathrm{p}<0,05)$, massa fresca comercial $(p<0,05)$, massa seca da parte aérea $(\mathrm{p}<0,01)$ e massa seca da raiz ( $\mathrm{p}<$ $0,05)$, ou seja, essas variáveis foram significativamente influenciadas pelos tratamentos.

Tabela 3. Médias de número de folhas (NF), altura de plantas (AP, cm), diâmetro caulinar (DC, mm), massa fresca da parte aérea (MFPA, g), massa fresca comercial (MFC, g), massa seca da parte aérea (MSPA, g) e massa seca da raiz MSR, g) da alface em função dos tratamentos aplicados.

\begin{tabular}{|c|c|c|c|c|c|c|c|}
\hline Tratamentos & $\mathbf{N F}$ & AP & DC & MFPA & MFC & MSPA & MSR \\
\hline & - & $\mathrm{cm}$ & $\mathrm{mm}$ & \multicolumn{4}{|c|}{...g. } \\
\hline$T_{1}-E B$ & $18,00 \mathrm{~b}$ & $9,67 \mathrm{a}$ & $13,52 \mathrm{ab}$ & $73,88 \mathrm{ab}$ & $69,32 \mathrm{ab}$ & $6,07 \mathrm{ab}$ & $0,90 \mathrm{ab}$ \\
\hline $\mathrm{T}_{2}-\mathrm{NPK}$ & $10,67 \mathrm{c}$ & $7,67 \mathrm{a}$ & $10,68 b$ & $39,98 b$ & $38,28 b$ & $2,71 b$ & $0,52 b$ \\
\hline $\mathrm{T}_{3}-\mathrm{U}$ & $16,00 \mathrm{bc}$ & $7,33 \mathrm{a}$ & $11,0 \mathrm{ab}$ & $67,77 \mathrm{ab}$ & $65,59 \mathrm{ab}$ & $4,22 b$ & $0,67 b$ \\
\hline $\mathrm{T}_{4}-\mathrm{M}$ & $19,67 \mathrm{ab}$ & $10,67 \mathrm{a}$ & $14,71 \mathrm{ab}$ & $98,31 \mathrm{ab}$ & $89,49 \mathrm{ab}$ & $8,17 \mathrm{ab}$ & $1,42 \mathrm{ab}$ \\
\hline $\mathrm{T}_{5}-\mathrm{U}+\mathrm{M}$ & $25,67 \mathrm{a}$ & $11,33 \mathrm{a}$ & $16,39 \mathrm{a}$ & $133,55 \mathrm{a}$ & $125,21 \mathrm{a}$ & $12,02 \mathrm{a}$ & $1,56 \mathrm{ab}$ \\
\hline $\mathrm{T}_{6}-2 \mathrm{xU}$ & $16,33 \mathrm{bc}$ & $8,67 \mathrm{a}$ & $12,77 \mathrm{ab}$ & $77,01 \mathrm{ab}$ & $72,97 \mathrm{ab}$ & $7,36 \mathrm{ab}$ & $1,19 \mathrm{ab}$ \\
\hline $\mathrm{T}_{7}-2 \mathrm{xM}$ & $20,67 \mathrm{ab}$ & $10,33 a$ & $15,18 \mathrm{ab}$ & $115,79 a$ & $112,35 \mathrm{a}$ & $9,84 a b$ & $2,13 \mathrm{a}$ \\
\hline $\mathrm{T}_{8}-2 \mathrm{xUM}$ & $18,67 b$ & $11,67 \mathrm{a}$ & $15,43 \mathrm{ab}$ & $102,46 a b$ & $91,28 \mathrm{ab}$ & $9,74 \mathrm{ab}$ & $1,79 \mathrm{ab}$ \\
\hline $\mathbf{F}$ & $9,43^{\text {** }}$ & $1,69^{\mathrm{ns}}$ & $3,70^{*}$ & $3,83^{*}$ & $3,77^{*}$ & $4,50^{* *}$ & $3,68^{*}$ \\
\hline CV\% & 13,31 & 22,45 & 13,37 & 29,73 & 29,66 & 33,63 & 39,72 \\
\hline
\end{tabular}

Médias seguidas de letras iguais, na coluna, não diferem entre si pelo teste de Tukey a 5\% de probabilidade. ns, **,* Não significativo, significativo a 1 e $5 \%$ de probabilidade pelo teste F.

Para à variável número de folhas (NF), as médias apresentaram diferença estatística entre si com o máximo valor de aproximadamente 26,00 folhas por planta, obtido através da fertirrigação com urina humana mais manipueira por vaso $\left(\mathrm{T}_{5}-\mathrm{U}+\right.$ M). Esse valor é bastante satisfatório, pois Martins et al. (2013) ao avaliar o uso de diferentes tipos e combinações de fontes orgânicas e fosfatadas aceitas por agricultura 
orgânica visando verificar aquelas mais promissoras para a cultura da alface obteve no máximo em média 21,00 folhas por plantas.

As médias da altura de plantas (AP) não apresentaram diferença estatística entre si, mas a máxima média foi de $11,67 \mathrm{~cm}$ obtida com a aplicação de duas vezes as doses de urina e manipueira $\left(\mathrm{T}_{8}\right)$. Valor semelhante foi encontrado por Chiconato et al. (2013) que objetivando avaliar o efeito de doses de biofertilizante de origem bovina (efluente de biodigestor) aplicadas no solo e de dois níveis de irrigação obtiveram $11,8 \mathrm{~cm}$ para a máxima altura de planta da alface fertirrigada com 60 $\mathrm{m}^{3} \mathrm{ha}^{-1}$ de biofertilizante.

Houve diferença estatística entre si para as médias do diâmetro caulinar (DC) com máximo valor $(16,39 \mathrm{~mm})$ que, como o número de folhas, também foi obtido através da fertirrigação com urina humana mais manipueira $\left(\mathrm{T}_{5}-\mathrm{U}+\mathrm{M}\right)$. Este valor foi inferior ao encontrado por Santi et al. (2013), que ao avaliarem o efeito de doses de torta de filtro nas características agronômicas de cultivares de alface americana, em ambiente protegido, obteve a máxima média de $18 \mathrm{~mm}$ de diâmetro caulinar.

As médias da massa fresca da parte aérea (MFPA) apresentaram diferença estatística entre si e as máximas médias foram obtidas através da fertirrigação do substrato com os tratamentos $\mathrm{T}_{5}$ (fertirrigação com $35 \mathrm{~mL}$ de urina $+114 \mathrm{~mL}$ de manipueira por vaso) e $\mathrm{T}_{7}$ ( $2 \times \mathrm{M})$. Efeito semelhante foi observado com as médias da massa fresca comercial (MFC). Os máximos valores de massa verde da parte aérea $\left(\mathrm{T}_{7}=115,76\right.$ e $\left.\mathrm{T}_{5}=133,55 \mathrm{~g}\right)$ foram próximos aos apresentados por Morales et al. (2013) que obtiveram 106,9 e 161, 2 g planta $^{-1}$ de massa verde da parte aérea da alface cultivada em substrato composto por resíduo de frigorífico em mistura com casca de arroz natural e casca de arroz carbonizada na proporção de $3: 1$, respectivamente.

Avaliando o uso de diferentes doses de manipueira na cultura da alface, em substituição à adubação mineral, Duarte et al. (2011) obtiveram máximas médias de massa fresca de 90,3 g planta $^{-1}$.
Para a massa seca da parte aérea (MSPA), a máxima média foi de $12,02 \mathrm{~g} \mathrm{planta}^{-}$ ${ }^{1}$, obtida através da fertirrigação com o tratamento $\mathrm{T}_{5}$ que apresentou diferença significativa entre si. Este valor foi superior ao obtido por Peixoto Filho et al. (2013), que ao avaliar a produção da alface em cultivos sucessivos em campo com o uso de estercos de frango, bovino e de ovino encontrou no máximo $6,69 \mathrm{~g}_{\text {planta }}{ }^{-1}$.

A máxima média da massa seca das raízes (MSR), de 2,13 g planta ${ }^{-1}$, foi obtida através da fertirrigação com duas vezes a dose de manipueira $228 \mathrm{~mL}$ por vaso $\left(\mathrm{T}_{7}\right)$ apresentando diferença significativa entre si. Essa variável apresentou valor superior ao encontrado por Araújo et al. (2011) que ao avaliarem os efeitos de diferentes doses de nitrogênio aplicadas via fertirrigação sobre alface cv. 'Verônica' (tipo crespa) obtiveram a máxima massa seca de raízes de $0,639 \mathrm{~g}$ planta $^{-1}$.

Em conformidade com o exposto, observa-se que a os melhores resultados foram alcançados através dos substratos fertilizados com urina humana mais manipueira, duas vezes a dose de manipueira e duas vezes as doses de urina mais manipueira indicando que há uma grande potencialidade para o cultivo da alface Crespa Cristina em substratos fertilizados com manipueira e/ou urina humana.

\section{CONCLUSÕES}

1. As variáveis de crescimento e produção da alface Crespa Cristina responderam positivamente as adubações com urina humana $\mathrm{e}$ manipueira, indicando que estes efluentes podem ser utilizados como fontes de fertilizantes alternativos para a cultura.

2. As fertirrigações que proporcionaram os melhores resultados foram as que continham urina humana mais manipueira $\left(\mathrm{T}_{5}\right) \mathrm{e}$ duas vezes a dose de manipueira $\left(\mathrm{T}_{7}\right)$. 
3. Para utilizar urina humana como fonte de nutrientes na cultura da alface é recomendável que sua coleta seja realizada em sistema separador absoluto, seguida por tratamento que promova a total inativação de possíveis microrganismos patogênicos.

\section{REFERÊNCIAS BIBLIOGRÁFICAS}

APHA - American Public Health Association; AWWA - American Water Works Association; WEF - Water Environment Federation. Standard Methods for the examination of water and wastewater. $21^{\text {st }} \mathrm{ed}$. Washington, DC: APHA, 2005.

ARAÚJO, W. F.; SOUSA, K. T. S.; VIANA, T. V. A.; AZEVEDO, B. M.; BARROS, M. M.; MARCOLINO, E. Resposta da alface a adubação nitrogenada. Revista Agro@mbiente On-line, v. 5, n. 1, p. 12-17, 2011.

ARAÚJO, N. C.; FERREIRA, T. C.; OLIVEIRA, S. J. C.; GONÇALVES, C. P.; ARAÚJO, F. A. C. Avaliação do uso de efluente de casas de farinha como fertilizante foliar na cultura do milho (Zea mays L.). Engenharia na Agricultura, v.20, n.4, p. 340 - 349, 2012.

ARAÚJO, N. C.; COURA, M. A.; OLIVEIRA, R.; SABINO, C. M. B.; OLIVEIRA, S. J. C. Cultivo hidropônico de milho fertirrigado com urina humana como fonte alternativa de nutrientes. Irriga, v. 20, n. 4, p. 718-729, 2015.

ARAÚJO, N. C.; OLIVEIRA, S. J. C.; FERREIRA, T. C.; LIMA, V. L. A.; QUEIROZ, A. J. P.; ARAÚJO, F. A. C. Crescimento e produtividade de milho fertilizado com manipueira como fonte alternativa de nutrientes. Tecnologia e Ciência Agropecuária, v.9, n.2, p. 31 - 35, 2015.
BARRETO, M. T. L.; ROLIM, M. M.; PEDROSA, E. M. R.; MAGALHÃES, A. G.; TAVARES, U. E.; DUARTE, A. S. Atributos químicos de dois solos submetidos à aplicação de manipueira. Agrária - Revista Brasileira de Ciências Agrárias, v.8, n.4, p.528-534, 2013.

BARRETO, M. T. L.; MAGALHÃES, A. G.; ROLIM, M. M.; PEDROSA, E. M. R.; DUARTE, A. S.; TAVARES, U. E. Desenvolvimento e acúmulo de macronutrientes em plantas de milho biofertilizadas com manipueira. Revista Brasileira de Engenharia Agrícola e Ambiental, v.18, n.5, p.487-494, 2014.

CHICONATO, D. A.; SIMONI, F.; GALBIATTI, J. A.; FRANCO, C. F.; CARAMELO, A. D. Resposta da alface à aplicação de biofertilizante sob dois níveis de irrigação. Bioscience Journal, v. 29, n. 2, p. 392-399, 2013.

DANTAS, M. S. M.; ROLIM, M. M.; DUARTE, A. S.; PEDROSA, E. M. R.; TABOSA, J. N.; DANTAS, D. C. Crescimento do girassol adubado com resíduo líquido do processamento de mandioca. Revista Brasileira de Engenharia Agrícola e Ambiental, v.19, n.4, p.350-357, 2015.

DUARTE, A. S.; SILVA, Ê. F. F.; ROLIM, M. M.; FERREIRA, R. F. A. L.; MALHEIROS, S. M. M.; ALBUQUERQUE, F. S. Uso de diferentes doses de manipueira na cultura da alface em substituição à adubação mineral. Revista Brasileira de Engenharia Agrícola e Ambiental, v.16, n.3, p.262-267, 2011.

EGIGU, M. C.; MELAK, B.; KEBEDE, A.; MUTHUSWAMY, M. Use of human urine as fertilizer for vegetable cultivation. International Journal of Agriculture Innovations and Research, v.3, n.1, p. $254-$ 258, 2014.

FERREIRA, L. G.; RIZENTAL, M.; DAL MOLIN, Í. A.; MONDIN, M.; NESSI JUNIOR, P. Produtividade de cultivares de 
alface em dois ambientes em Varzea GrandeMT. Connection Line, n. 13, p. 24 - 35, 2015.

LEAL, F. R. R.; LEAL, M. P. C.; ALBUQUERQUE, C. L. C. D. Avalição do efeito da manipueira em aplicação vias foliar e substrato na produção de coentro. Cadernos de Agroecologia, v. 10, n.3, 2015.

MARTINS, I. S.; SILVA, I. M.; FERREIRA, I.; MELO, L. F.; NOMURA, M. Produtividade da alface em função do uso de diferentes fontes orgânicas fosfatadas. FAZU em Revista, n.10, p. 36-40, 2013.

MORALES, D. A.; SANTANA, N. A.; ANTONIOLLI, Z. I.; JACQUES, R. J.; KIRST, G. P.; STEFFEN, R. B. Utilização dos diferentes vermicompostos produzidos a partir de resíduos da estação de tratamento de efluentes como substrato para produção de mudas de alface. Ciência e Natura, v. 35, n. 1, p. 055-063, 2013.

NOVAIS, R. F.; NEVES, J. C. L.; BARROS, N. F. Ensaio em ambiente controlado. In: Oliveira, A. J. (ed.) Métodos de pesquisa em fertilidade do solo. Brasília: Embrapa-SEA p. 189-253, 1991.

OLIVEIRA, E. Q.; SOUZA, R. J.; CRUZ, M. C. M.; MARQUES, V. B.; FRANÇA, A. C. Produtividade de alface e rúcula, em sistema consorciado, sob adubação orgânica e mineral. Horticultura Brasileira, v.28, n.1, p. 36-40, 2010.

PEIXOTO FILHO, J. U.; FREIRE, M. B. G. S.; FREIRE, $\quad$ F. J.; MIRANDA, M. F. A.; PESSOA, L. G. M.; KAMIMURA, K. M. Produtividade de alface com doses de esterco de frango, bovino e ovino em cultivos sucessivos. Revista Brasileira de Engenharia Agrícola e Ambiental, v.17, n.4, p.419-424, 2013.

PESSUTI, C. A. A.; HERMES, E.; NEVES, A. C.; SILVA, R. P.; PENACHIO, M. ZENATTI, D. C. Diferentes doses de biofertilizante proveniente da digestão anaeróbia de efluente de processamento de mandioca no cultivo de soja. Revista Gestão \& Sustentabilidade Ambiental, Ed. especial, v. 4, p.556-564, 2015.

PRADHAN, S. K.; NERG, N.; SJÖBLOM, A.; HOLOPAINEN, J. K.; HEINONENTANSKI, $\mathrm{H}$. Use of human urine fertilizer in cultivation of cabbage (Brassica oleracea) impacts on chemical, microbial, and flavor quality. Journal of agricultural and food chemistry, v. 55, n. 21, p. 8657-8663, 2007.

RIOS, É. C. S. V. Uso de águas amarelas como fonte alternativa de nutriente em cultivo hidropônico da alface (Lactuca sativa). 109 f. 2008. Dissertação (Mestrado em Engenharia Ambiental) - Universidade Federal do Espirito Santo. Vitória, ES, 2008.

SANTOS, M. H. V.; ARAÚJO, A. C.; SANTOS, D. M. R.; LIMA, N. S.; LIMA, C. L. C.; SANTIAGO, A. D. Uso da manipueira como fonte de potássio na cultura da alface (Lactuca sativa L.) cultivada em casa-devegetação. Acta Scientiarum Agronomy, v. 32, n. 4, p. 729-733, 2010.

SANTOS JÚNIOR, J. A.; SOUZA, C. F.; PÉREZ-MARIN, A. M.; CAVALCANTE, A. R.; MEDEIROS, S. S. Interação urina e efluente doméstico na produção do milheto cultivado em solos do semiárido paraibano. Revista Brasileira de Engenharia Agrícola e Ambiental, v.19, n.5, p.456-463, 2015.

SANTOS, O. S. N.; TEIXEIRA, M. B.; QUEIROZ, L. M.; FADIGAS, F. S.; PAZ, V. P. S.; SILVA, A. J. P.; KIPERSTOK, A. Nitrogen recycling through fertilization of Bermuda grass using human urine diluted in water. Revista Brasileira de Agroecologia, v.11, n.3, p. 164-171, 2016.

SANTI, A.; SCARAMUZZA, W. L. M. P.; NEUHAUS, A.; DALLACORT, R.; KRAUSE, W.; TIEPPO, R. C. Desempenho agronômico de alface americana fertilizada com torta de filtro em ambiente protegido. 
Horticultura Brasileira, v.31, n.2, p. 338$343,2013$.

SILVA, F. A. M.; VILAS-BOAS, R. L.; SILVA, R. B. Resposta da alface à adubação nitrogenada com diferentes compostos orgânicos em dois ciclos sucessivos. Acta Scientiarum Agronomy, v.32, p.131-137, 2010 .

SILVA JUNIOR, J. J.; COELHO, E. F.; SANT'ANA, J. A. V.; SANTANA JUNIOR, E. B.; PAMPONET, A. J. M. Uso da manipueira na bananeira 'terra maranhão' e seus efeitos no solo e na produtividade. Irriga, v. 17, n. 3, p. $353-363,2012$.

SILVA, F. A. S.; AZEVEDO, C. A. V. They assistat software version 7.7 and its use in the analysis of experimental data. African Journal of Agricultural Research (AJAR), v. 11 , n. 39, p. $3733-3740,2016$.

SCHWENGBER, J. A. M.; SILVA, F. F.; SMIDERLE, O. J.; SCHWENGBER, D. R. Nodulação do feijão-caupi em função da aplicação de três águas de farinheira. Revista em Agronegócios e Meio Ambiente, v.3, n.2, p. 135-146, 2010. 